\title{
Health Impact of Rights Violations in Conflict Zones and the Humanitarian Imperative: Rwanda-A Case Study
}

\author{
Dr. James Orbinski
}

I will address the health impact of rights violations in conflict situations and the link between health and human rights. I will do this using Medecins Sans Frontières' (MSF) experience in Rwanda as a starting point, and I hope to draw generic principles from this case in order to look at the nature and mechanisms of the humanitarian imperative in today's global context, and what this could mean for further efforts to define humanitarianism in the future.

As many will know, MSF is an international humanitarian organization that provides medical aid without discrimination to populations in crisis. ${ }^{1}$ We rely on volunteer professionals and are independent of all states and institutions, as well as of all political, economic, or religious affiliations. The organization grew out of the frustration of a group of French doctors working in Biafra during the crisis of 1971. They were outraged that governments and nongovernment organizations (NGOs) were powerless to stop the forced starvation and displacement of millions of people, because such an effort would contravene existing international statutes and bodies of law. This initial contempt for established legal systems has spawned a global organization which, at any one time, has over 2,000 volunteers working with over 14,000 nationals in 70 countries today.

Like the International Red Cross and a legion of other NGOs, MSF

Dr. James Orbinski is the vice-president, Médecins Sans Frontieres (Doctors Without Frontiers) Canada, and an associate at the Centre for International Health, McMaster University, Hamilton, Ontario.

This paper was presented at the First International Conference on Health and Human Rights, HarvardUniversity, Cambridge, Massachusetts, USA worked in the Cold War era with a commitment to providing humanitarian assistance to people in need. Unlike other NGOs, however, MSF frequently engaged in cross-border activities that violated state sovereignty to provide that assistance. Over time, this humanitarian imperative has evolved from a concept to customary behaviour that is accepted in international law. In the post-cold war world, MSF has developed its policy of speaking out against massive human rights abuses, most notably in Somalia in 1992-93, the former Yugoslavia, southern Sudan and, this year, in Rwanda. I was directly involved in Somalia and Rwanda in both political and medical management roles, and will share some of my reflections on these experiences.

If I were to speak in purely theoretical terms, the human dimension of the issues would be lost-and it is this dimension that is central to the principles of human rights and the humanitarian imperative derived therefrom. I believe the best way to address the issues I have outlined is to describe some of my own experiences as Chief of Mission for MSF in Rwanda. MSF is one of the world's largest independent medical relief organizations and, in Rwanda this year, we continue to be engaged with the largest humanitarian disaster we have ever assisted in. I will describe only one of my days, and the variety of events and issues that ran through that 24 -hour period on June 17, 1994.

On that day, we had MSF teams working in both Rwandan Patriotic Front (RPF) and Rwandan Government Forces (RGF) territory throughout the country. With the exception of a poorly supported UN ceasefire monitoring force, the international community left Rwanda in early April, after the assassination of the Rwandan president. Only MSF and the Red Cross remained in Rwanda at that time, but a host of other NGOs were working in neighbouring Zaire, Uganda, Tanzania, and Burundi. That morning, after speaking for two hours via satellite telephone with MSF headquarters in Amsterdam, Paris, Brussels, and Toronto, I climbed into a UN armoured personnel carrier (APC) to attempt medical examinations and to deliver medical supplies to orphanages, churches, and schools on the other side of the front line in Kigali. These locales were sheltering Tutsi people from RGF militia, who would cull the churches at night, butchering hundreds, and sparing those who could come up with 40 US dollars, or who were spared by grace alone. Like many other mornings, ill-equipped UN soldiers crossed active fighting on the front line in Kigali, braved rockets, mortars, and shells fired directly at them, and moved through throngs of drunken machete- and gun-wielding militiamen at multiple checkpoints on the other side of the front line. Why? To give credence, if only symbolically, to the humanitarian imperative-to the rights of those people who literally cried with fear each day. We arrived at the Saint Michel Orphanage, one of many we visited that day. I got out of the APC and was greeted by the sneering eyes and physical cajoling of the Interyhamwe militia. The UN soldiers, who themselves were pushed and jeered, encircled me as we made our way into the orphanage. Inside, 119 children remained. The night before, 240 children and adults had been butchered here. These 119 sat in an open compound, each one alone, amidst the horror of all horrors. One little boy, about five years old, had both his ears cut off and a machete 
blow through his right eye. The left side of his body was paralyzed, and I wondered, as I examined him, what does it take to hold a child while he screams in terror, and wilfully and repeatedly destroy his body, not with a gun, but with the raw rage of a machete in hand? The boy smiled at me, and I could only return his smile.

At 2 p.m., I was looking out on over 600 casualties, mostly women and children, who were laid out on the road outside the school where a makeshift hospital and surgical unit had been set up. The gutters literally ran with blood, and the sweet smell of open flesh coursed through the hot African air. We worked in a fixed, concentrated way, inserting chest tubes, tying off bleeding arteries, closing eviscerated bleed to death and not be able to climb out of the graves.

That evening, a nine-year-old girl, who had been brought to the hospital in the early stages of malnutrition, told me that "my mother hid me in the toilet. I saw through the hole, and watched them hit her with machetes. She was bleeding on top of my father who was dead, and I cried without noise. I stayed under the toilet for three days because there was anger in the village that was my home."

The following morning at our hospital in RPF territory there were, among our 500 patients, 90 badly injured Interyhamwe militia, who had butchered people like this little girl's parents, and the little boy at the orphanage. These 90 patients had been abdomens on the road, and marking the foreheads of scores of living casualties on the roadside with the number " 3 ," meaning irretrievable. We ran medical supplies through the front line from one hospital to another using UN APC's, and we ran the operating room as the shelling continued into the night. The field hospital was hit repeatedly by high-calibre bullets and, as heavy fighting continued, the emergency room was destroyed by shell fire the next morning.

At the same time, during a six-week period, over one million people were being butchered in the city of Kigali and around the country. They were butchered in a systematic, rational way, with militia being trucked in to facilitate the efficient elimination of the Tutsi Inyenzi-the Tutsi insects-as the militia called them. Mayors and civic officials provided lists of names and addresses, and people were killed in their homes or, more often, transported or marched to mass graves, where they were not shot, but had their hands and feet cut off so they would brought to the RPF side of the front line in transport trailers during a temporary ceasefire, which the Chief of Mission for the ICRC, the UN force commander General D'Allaire, and myself had negotiated with the RPF and RGF forces.

The hospitals were also filled with thousands of civilians who sought shelter for fear of enemy reprisals outside hospital grounds. You can imagine the complexity of negotiating with commanders and soldiers who repeatedly entered the hospital grounds armed, and proceeded to interrogate civilians and to arrest military and militia personnel undergoing surgical and medical care. Both sides were also taking medical equipment and supplies from hospitals to care for their own soldiers, and had set up mortar sites behind hospitals to shell enemy territory. Naturally, the other side tried to counter-shell these sites, and stray shells came within meters of the hospital. My repeated requests to move the mortar sites were met with comments such as, "I thought you were a doctor, since when do you advise us on military tactics?"

In hospitals around the country medical equipment was in such short supply that maggots were feeding on the wounds of patients who had not had their bandages changed. I remember vomiting after removing the infested dressings from the chest of a little girl injured by shrapnel. Both the RPF and the RGF hindered MSF or Red Cross air and land supply lines, and all movements of personnel in the country were being hampered by "new rules" and demands for nonexistent or unobtainable documentation at check stops.

At the same time, the RGF had announced on its radio that MSF personnel were assisting the enemy and were therefore not welcome in RGF territory. Rumour had it that a white MSF arm was worth 20 US dollars, and that a pair of arms would fetch 50 US dollars. Our vehicles were being directly targeted by attack helicopters in RGF territory. At the same time, in both territories, MSF was being accused of spying for the French, and my personnel were being turned away at the border, held for questioning for extended periods inside Rwanda, searched and harassed at checkpoints, while Rwandan nationals working with us were being taken out of hospitals and killed in the night. We assessed each situation, each risk, each threat according to the overall context, and either left MSF teams in place, withdrew them to safer locations within the country, or evacuated them completely, all the while trying to maintain the humanitarian imperative.

As I detailed events to our offices in Amsterdam, Paris, Brussels, and Toronto, MSF personnel were lobbying heads of state, the US State Department, and the Security Council for a multinational military intervention to stop the genocide, establish law and order, and support a system of national or international justice. A few weeks later, after intense international waffling, the French arrived in Rwanda as a de facto unilateral force with a Chapter 7 mandate to establish a humanitar- 
ian safe zone in southwest Rwanda. No one was clear on the French motivesthe RGF were celebrating in the streets expecting French military support, the RPF were preparing to battle the French, and the UN ceasefire force under Chapter 6 was watching the situation and preparing for all eventualities. A few weeks later, over 1 million people fled across the border into Zaire in fear of RPF reprisals, setting off the largest and fastest refugee movement in this century. Two thousand refugees were dying every day of cholera, dysentery, and thirst. During all this, we followed the same strategy of risk assessment and management while attempting to maintain the humanitarian imperative.

In assessing the health impact of rights violations in conflict situations, and particularly in Rwanda, the link between health and human rights is self-evident. Health defines a humane way of pursuing life itself and is, without question, the fundamental human right. Overall, 1.2 million people were murdered in an act of genocide, thousands of civilians died as direct casualties in the bloodiest civil war of this century, millions were displaced within Rwanda, and millions remain as refugees outside Rwanda in Zaire, Uganda, and Tanzania. Cholera, dysentery, malnutrition, and malaria strike in epidemic waves of previously unknown proportions. Rwanda's cities, roads, and farmland are covered with land mines and, most important, social stability through a system of law, order, and a national and international system of justice-the necessary precursor to rebuilding-remains a distant hope.

No amount of medicine or health infrastructure will ever begin to cope even minimally with these realities until people go home. And people will not go home because they are afraid for their lives, for their physical, social, and mental wellbeing, and for their dignity and rights as human beings. The single most important factor delaying stability in Rwanda today is not lack of food, water, or medicine, but the absence of UN human rights moni- tors. Quite simply, people are ready to face justice, but fear injustice. They fear that the guilty will go free or that the rebels will exact retribution on the innocent and guilty alike.

Humanitarian principles, imperatives, and mechanisms must be clearly defined, at least in the minds of those who engage in humanitarian work and advocacy. So what is this concept called the humanitarian imperative? It is clearly an operational derivative of the link between the principles of health and human rights. It demonstrates the right to work for the benefit of others without the wish to do harm. The mechanisms of this imperative are independence, neutrality, and impartiality. It can be argued that the hu- state armed conflict, and not to a conflict within a sovereign state.

Yet the 1986 International Court of Justice ruling, ${ }^{5}$ and four post-cold war Security Council resolutions ${ }^{6}$ confirmed the right of impartial access by humanitarian organizations in Nicaragua, Iraq, Bosnia and Herzegovina, Somalia, and most recently in Rwanda-all either interstate or civil war conflicts. The established laws, rulings, and resolutions not only legitimize humanitarian access and the right of people to receive assistance, but also the humanitarian imperative itself and the link between the principles of health and human rights. They explicitly affirm that the humanitarian imperative overrides sovereignty manitarian imperative and its mechanisms have become legitimized-although somewhat nebulously-in international law and expected codes of conduct.

International law is not static. It changes as societies change through history and, in our century, it emerges from four sources: first and most important, the UN Charter; the second is the law of treaty between states; the third is derived from generally accepted principles and decisions of international courts; and the fourth is derived from customary law, which means simply that an established custom of behaviour or principle can be used as a basis for defining the future nature of custom or principle.

Under the UN Charter, ${ }^{2}$ and two General Assembly resolutions of $1988,{ }^{3}$ humanitarian assistance is clearly an obligation of states. Under the Four Geneva Conventions of 1949 and the Two Protocols of 1977,4 it is a victim's right to receive assistance, and the right of humanitarian organizations to offer assistance. However, this body of law applies only during inter- when that sovereignty is not capable or willing to meet the basic health needs of its population. Remember that international law is not static, and that what was, in the Cold War era, behaviour on the fringes of international law has in fact, by virtue of established custom, become law.

So it is the humanitarian imperative, its principles, and mechanisms that both drive and allow humanitarian organizations to work where human rights are violated or threatened. In terms of emerging trends in established humanitarian and customary law, the most dangerous thing is to do or say nothing when human rights are violated. When context overpowers the ability to act effectively on behalf of the humanitarian imperative, as in Rwanda, the imperative changes from a focus on individual people in need of assistance to a focus on the political context in which this overwhelming need arises. It is in this context of massive rights violations where advocacy becomes a mechanism of the humanitarian imperative, where advocacy must demand that responsibility to 
protect human rights be assumed, and it is here where the humanitarian mechanisms of independence, impartiality, and neutrality are most challenged. As my Rwanda account illustrates, these latter mechanisms, recognized in established and customary international law, were certainly challenged. It was not and is not easy, but we and other humanitarian organizations did and are doing what we set out to do-act in accordance with the humanitarian imperative. and international system of justice may be a military issue with clear humanitarian implications.

This issue speaks to the broader context of "globalism versus nationalism" and the sovereignty of states, which is a defining concept of our age. Human society is not and never has been static. It is always fluid and changing, and ours is clearly a world of paradox, where traditional nation-state structures and internal belief systems are at odds with growing global issues which

\section{In my opinion, humanitarianism is not a military issue. But in a world where many nations sit on the brink of anarchy and where brutality has become the norm, law, order, and support for a national and international system of justice may be a military issue with clear humanitarian implications.}

Impartiality, neutrality, and independence are not a license for passivity. These mechanisms do not imply that humanitarian organizations shall remain silent in the face of gross human rights violations. They imply that, in such circumstances, humanitarian organizations must remain neutral, impartial, and independent of influence in their recognition of the sanctity of the rights and the responsibilities inherent in the humanitarian premise. These mechanisms then, quite simply, become a means of counteracting inhumanity with humanity and, where this is impossible, of witnessing on behalf of the humane.

The danger, of course, in engaging advocacy on behalf of humanitarianism is not that it becomes the political issue that it should be, but that it becomes subject to political manipulation by states acting in their national or regional interests. This argument has certainly been made in the post-cold war world, and the quagmire of confusion around NGOs, UN agencies, and UN forces in Iraq, Somalia, the former Yugoslavia, and now Rwanda is further evidence of this. In my opinion, humanitarianism is not a military issue. But in a world where many nations sit on the brink of anarchy and where brutality has become the norm, law, order, and support for a national command our attention, and cannot be solved with traditional ideologies and mechanisms.

Just as the nation-state formed out of a need to protect networks of people-bound together by evolving economy, culture, and religion-the new world can evolve to protect that same network now emerging on a global scale. It is impossible, however, to ignore or forget tradition. The nationstate will not disappear, but can evolve incrementally with a new integrity firmly rooted in the valence of transnational global issues and values. The most important of these is the growth of humanitarianism as a basic principle of global social order, and it is a principle that is only beginning to take shape. There certainly is within societies, cultures, and religions a strong rootedness in humanitarianism, but its global face has yet to be clearly seen.

And how might this face emerge? A poet has written, "To every question why, there is a resounding Yes," which I take to mean that the ideal is possible, but we just have to figure out how to reach it. Given what I have said about humanitarianism, its imperative, its principles, and its mechanisms, I think it is clear that the UN should not define the issue of humanitarianism, but evolve to provide mechanisms with which the issue can be operationalized and codified into systems and bodies of law. The UN should become the mechanism or broker of humanitarianism in our world, and it should not be co-opted by superpowers or regional state interests. Nor should humanitarianism be co-opted by the UN for political purposes.

The UN is truly our only mechanism of hope, albeit imperfect and in need of reform. It is a very young mechanism, less than 46 years in a human history that spans scores of millennia. The role of NGOs, humanitarian organizations and, I believe, universities as well, is to force, push, and cajole the defining and shaping of humanitarianism as a global issue so that, through UN mechanisms, humanitarianism becomes an operational and enforceable global imperative.

For the little boy at the orphanage, the little girl who hid in the toilet, and millions of Rwandans, there is no suffering more terrifying-more inhuman-than the suffering inflicted by another human being. As Burke said, "all that is required for evil to triumph is that good men do nothing". " Our challenge in addressing the health impact of rights violations in conflict zones is to ask what we can do and, quite simply, do it.

\section{Notes}

1. Destexhe, Alain. Médecins Sans Frontières Activity Report 1993-1994, Group Graphique Chauveheid, Brussels, Belgium. 1994.

2. Articles 1, 55, and 56, United Nations Charter, 1948.

3. Resolutions 43 and 131 , United Nations General Assembly, 1988.

4. Article 70, First Protocol of the Geneva Conventions, 1977.

5. Case Concerning Military and Paramilitary Activities In and Against Nicaragua (Nicaragua v. USA), International Court of Justice (1986) p. 125 para. 243.

6. Security Council Resolution 688, (1991), para. 3; Security Council Resolution 771, (1992), para. 4; Security Council Resolution 751 (1992), para. 14.

7. Burke, Edmund. 1770. "Thoughts on the Cause of the Present Discontents." In Bartlett's Familiar Quotations, 15th ed., Little, Brown and Co., 1980. 